\title{
A UNIQUE MUSCULOCUTANEOUS AXILLARY ARCH MUSCLE COMPRESSING INTERCOSTOBRACHIAL NERVE: A POSSIBLE REMNANT OF PANNICULUS CARNOSUS? - A CASE REPORT
}

\author{
Shweta Chaudhary1, Rishi Kumar Bharti², Hemali Desphande 3 \\ ${ }^{1}$ Assistant Professor, Department of Anatomy, College of Medicine. \\ ${ }^{2}$ Assistant Professor, Department of Community Medicine, College of Medicine. \\ ${ }^{3}$ Assistant Professor, Department of Anatomy, College of Medicine.
}

\section{ABSTRACT}

Many case reports have been reported in the past. The present case describes a rare finding of unique Musculocutaneous Axillary Arch Muscle (AAM) having cutaneous origin as its unique feature describing it to be atavistic and was seen to compress specially intercostobrachial nerve along with neurovascular bundle in axilla. Cutaneous origin relates back to be leftover of subcutaneous muscle, i.e. panniculus carnosus which may have served protective function in pectoral and axillary region in lower animals. Knowledge of these variations are of great significance, while performing surgical and radiological procedures in axilla and must be investigated before operating, so as to aid full exposure of area and avoid unnecessary complications.

\section{KEYWORDS}

Musculocutaneous Axillary Arch Muscle, Panniculus Carnosus, Atavistic, Pectoral Region, Upper Limb Muscles.

HOW TO CITE THIS ARTICLE: Chaudhary S, Bharti RK, Desphande H. A unique musculocutaneous axillary arch muscle compressing intercostobrachial nerve: a possible remnant of panniculus carnosus? - a case report. J. Evolution Med. Dent. Sci. 2016;5(72):53265328, DOI: $10.14260 /$ jemds/2016/1207

\section{INTRODUCTION}

Plenty of case reports having axillary arch muscle have been reported in the past. But such high incidence fails to provide any satisfactory explanation of its origin. Ramsay first described the axillary arch muscle in 1795.(1) In 1884, it was referred to as the axillary arch of Langer.(2) The muscle is described as a muscular axillary arch, 7-10 cm in length and 5-15 mm in breadth, crossing from the edge of latissimus dorsi, midway in the posterior fold over the front of the axillary vessels and nerves to join the tendons of pectoralis major, coracobrachialis or the fascia over the biceps. (3) Here, we report a unique muscle with cutaneous attachment which emphasises it to be embryological remnant of panniculus carnosus and seems to be atavistic in nature.

\section{CASE REPORT}

The purpose of present commentary is to report a unique musculocutaneous AAM with a slip arising from skin on left side, which was encountered during routine cadaveric dissection of 45 yrs. old female cadaver who died of pneumonia. The unique finding of musculocutaneous AAM arose mainly from latissimus dorsi muscle (B) and unique slip arising from AAM and seemed to merge with overlying axillary skin (Large Black Arrow in Figure 1 and 2). Cutaneous slip arising from AAM was $1.5 \mathrm{~cm}$ in length and $0.5 \mathrm{~cm}$ at broadest point. It had other attachment with fascia over short head of biceps (C). Strikingly, muscle showed no relation with coracoids process. Large variant muscle was measured to be $7.5 \mathrm{~cm}$ in length and $1.5 \mathrm{~cm}$ at broadest point. It was supplied by thoraco-dorsal nerve and blood supply was coming from superior thoracic artery.

Financial or Other, Competing Interest: None.

Submission 29-07-2016, Peer Review 21-08-2016,

Acceptance 29-08-2016, Published 08-09-2016.

Corresponding Author:

Shweta Chaudhary,

Abha,

Saudi Arabia.

E-mail: drshwetarishi@gmail.com

DOI: $10.14260 /$ jemds/2016/1207

\section{(c) (i) $($ )}

The variant musculocutaneous muscle was covering all neurovascular bundle (F) and especially seen to compress intercostobrachial nerve (E). Intercostobrachial nerve arose from second intercostal space and supplied upper one-third of the arm. The AAM was having musculotendinous fibers along with cutaneous slip.

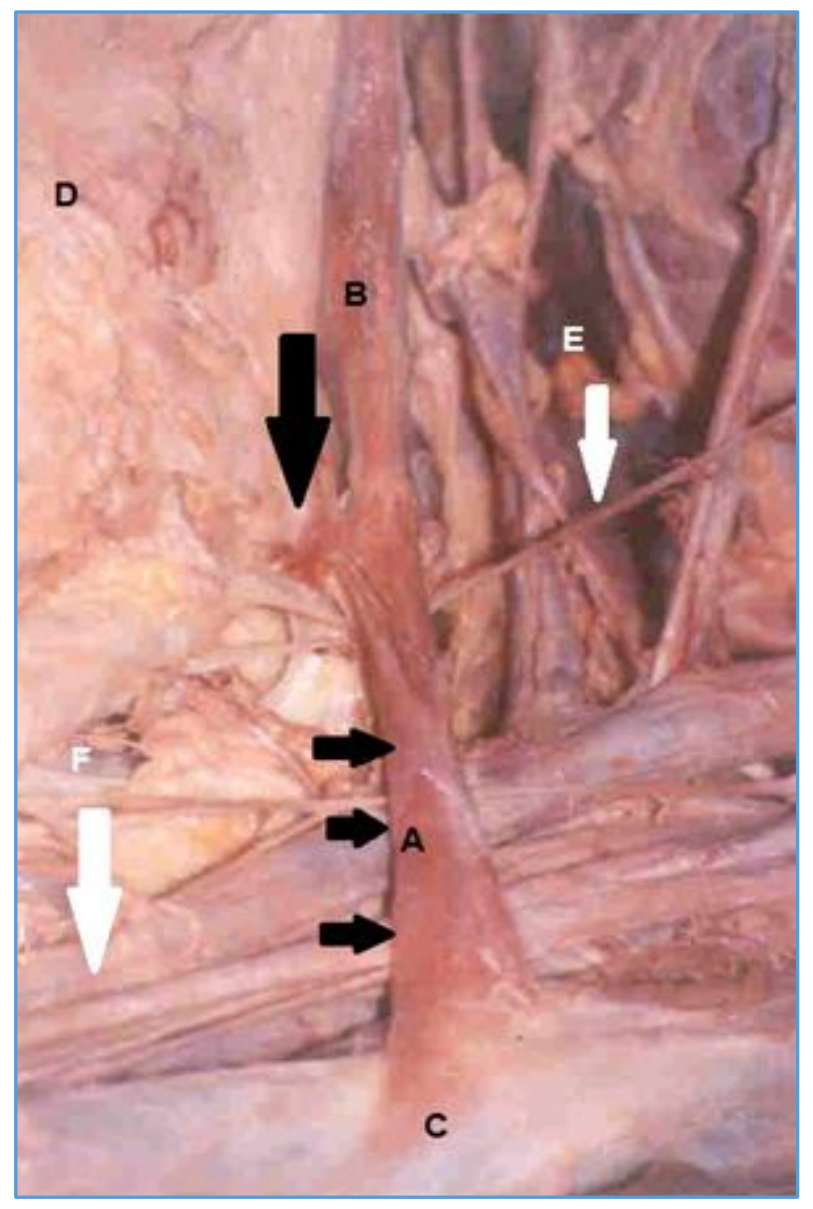

Fig. 1: Showing A - Axillary Arch Muscle (AAM), B Latissimus Dorsi, C - Short Head of Biceps Brachii, D Overlying Axillary Skin and Fascia,

E - Intercostobrachial Nerve and F- Neurovascular Bundle Passing below AAM, Large Black Arrow shows Cutaneous Slip from $A A M$ 


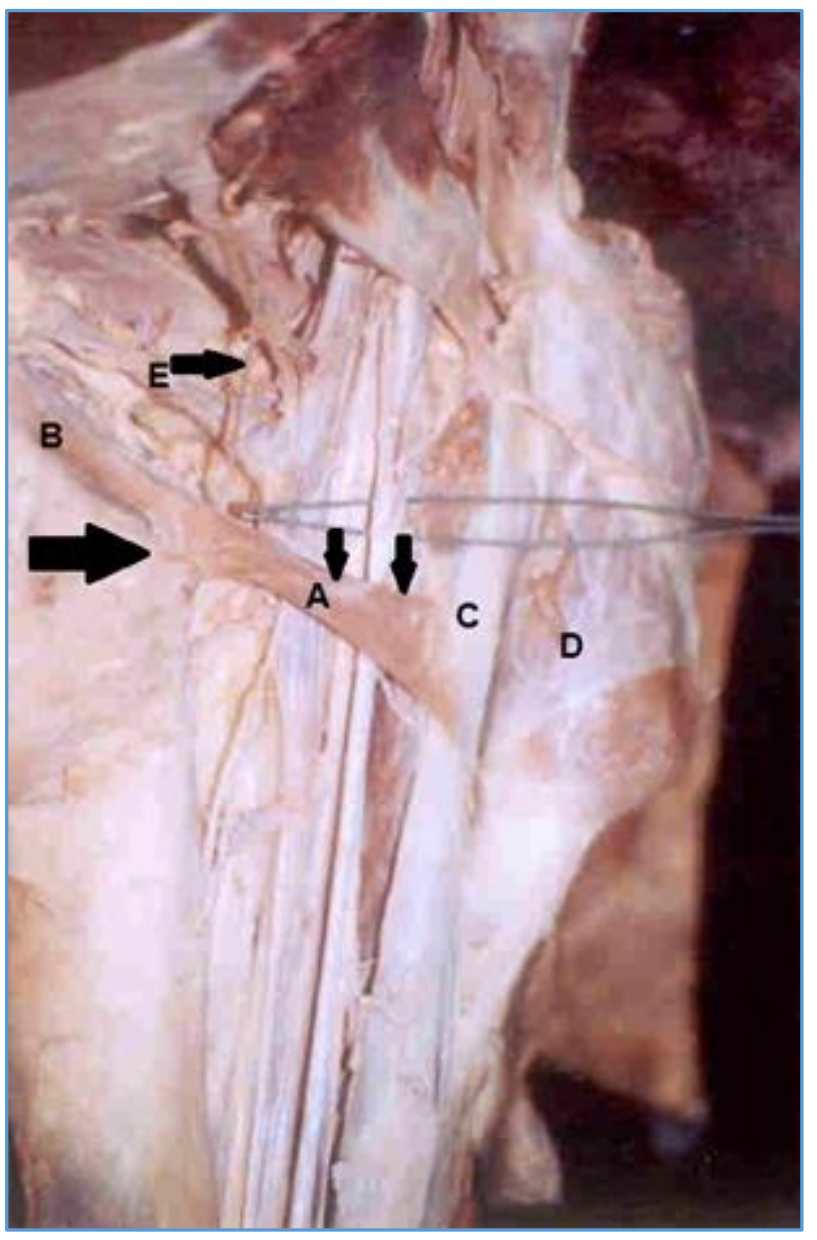

Fig. 2: Showing A - Axillary Arch Muscle (AAM), $B$-Latissimus Dorsi, $C$-Short Head of Biceps Brachii, D - Pectoralis Major (Reflected), E - Intercostobrachial Nerve. Passing below AAM, Large Black Arrow shows Cutaneous Slip from $A A M$

\section{DISCUSSION}

Limb muscles develop in situ from mesenchyme around the developing bones; this mesenchyme being derived from the somatic layer of the lateral plate mesoderm described 4 fundamental phases in the ontogenesis of muscle pattern. The muscle anomaly described here could have arisen during phases 3 and 4 of ontogenesis of the muscles in the left axilla. During phase 3 , some muscle primordia from different layers fuse to form a single muscle.(4)

Bharambe reported an incidence of AAM to be $3.33 \%$. They believed it to be atavistic in nature and an embryological remnant of panniculus carnosus. (5)

Soubhagya reported presence of co-existence of double variant in the same area. Anomalous latissimocondyloideus muscle was seen with rare variant of the axillary artery lying beneath the anomalous muscle. They found that the third part of the axillary artery beneath the AAM muscle was having anomalous branching pattern and in certain cases of obliteration of the radial pulse with depression of the shoulder may be due to axillary artery passing between the two roots of the median nerve.(6)

Muscular slips arising from latissimus dorsi or pectoralis major may insert into many structures including the fascia or flexor muscles of the arm. (7) Similarly, in our case it arose from latissimus dorsi and skin to insert to short head of biceps and coracobrachialis.
Loukas showed axillary arch originated from the latissimus dorsi with extensive branching, inserting into three of the more common sites; the pectoralis major, pectoralis minor and coracoid process. ${ }^{(8)}$

Daniels and Rovere have described the importance of being aware of variations of the axillary arch while performing lymphadenectomy for breast carcinoma, and the potential for the inadequate clearance of level 1 nodes as a result of coverage of the nodes by the variant muscle.(9)

Sachatello was the first to suggest a role for the axillary arch muscle in the hyperabduction syndrome; reported a patient with high-grade intermittent obstruction of the axillary vein due to the anomalous AAM. This muscle was extending from the latissimus dorsi to the insertion of the pectoralis major and overlaid the neurovascular bundle.(10)

Aziz's report of bilateral axillary arch muscle in a case of trisomy 13 and aneuploidy (trisomy 18), the variant AAM, was found along with other supernumerary muscles, a regular feature found in monkeys and great apes. It was believed that these supernumerary muscles may be "atavistic" structures. He showed it to be genetically associated. He believed that these supernumerary muscles may be "atavistic" structures.(11,12)

Regarding the possible genesis of AAM, various theories were proposed. In lower mammals the panniculus carnosus was very well developed to form the pectoral group of muscles. With evolution these muscles had regressed due to reduced functional importance. Langer's arch could be an embryological remnant of the panniculus carnosus in the axillary region.(13) Pressure by the muscle during contraction can cause axillary vein entrapment, lymphatic compression with subsequent venous thrombosis or lymphoedema.(14) Contracture of such muscle may lead to restricted abduction of arm. Our case strikingly supports it to be remnant of panniculus carnosus as here we clearly appreciate its cutaneous attachment, which has not been reported in past. Thereby, supporting it to be atavistic in nature, which may have served protective function in lower animal and became atavistic due to erect posture or reduced role of upper limb in walking as compared to quadrupeds. Such variations could be significant to surgeons operating in axilla for carcinoma of breast or for drainage of axillary abscess. Radiologists and surgeons should be aware of such variations. Particularly, in light of the increasing number of arterial interventions, knowledge of normal and variant anatomic features has become more important than in the past.

\section{CONCLUSION}

Preoperative awareness of such variations on the part of the surgical team is extremely important for complete exposure of lymph nodes and fat ensuring complete removal of affected tissue. AAM seem to be atavistic in nature and attachment to skin proves it to be remnant of panniculus carnosus. At present every practicing radiologist and surgeon must have in-depth knowledge of such variations for better understanding of associated clinical conditions, such as thoracic outlet and hyperabduction syndrome and during their treatment. Further research about its genesis along with genetic analysis should be performed in future, so as to describe its wide incidence. This would help for better understanding of these variant entities. 


\section{REFERENCES}

1. Bergman RA, Thompson SA, Afifi AK, et al. Compendium of human anatomic variation. Catalog, atlas and world literature. Urban \& Schwarzenberg. Baltimore and Munich, 1988.

2. Testut L. Les anomalies muscularies chez l'homme expliqués par i'anatomie compare, Paris: Masson, French. 1892.

3. Standring S. Pectoral girdle and upper limb in Gray's anatomy. In: Borley NR, Healy JC, Collins P, et al. eds. $40^{\text {th }}$ edn. Churchill Livingstone: Elsevier 2008:777-906.

4. Hamilton WJ, Hamilton MHW. Boyd and Mossman's human embryology. $4^{\text {th }}$ edn. London: Macmillan 1972:557-9.

5. Bharambe VK, Arole V. The axillary arch muscle (Langer's muscle): clinical importance. Med J 2013;6(3):327-30.

6. Nayak SR, Prabhu LV, Madhan AK, et al. Coexistence of an axillary arch muscle with an unusual axillary artery branching: case report and review. Int J Morphol 2006;24(2):147-50.

7. Hollinshead WH. Anatomy for surgeons. $3^{\text {rd }}$ edn. Philadelphia: Harper and Row 1982;3:280-1.
8. Loukas M, Noordeh N, Tubbs RS, et al. Variation of the axillary arch muscle with multiple insertions. Singapore Med J 2009;50(2):e88-90.

9. Daniels IR, Della Rovere GQ. The axillary arch of Langer-the most common muscular variation in the axilla. Breast Cancer Res Treat 2000;59(1):77-80.

10. Sachatello CR. The axillopectoral muscle (Langer's axillary arch): a cause of axillary vein obstruction. Surgery 1977;81(5):610-2.

11. Aziz MA. Anatomical defects in a case of trisomy 13 with a D/D translocation. Teratology 1980;22(2):217-27.

12. Aziz MA. Muscular and other abnormalities in a case of Edward's syndrome (18-Trisomy). Teratology 1979;20(2):303-12.

13. Bergman AR, Afifi AK, Miyauchi R. Latissimus dorsi. Illustrated encyclopedia of human anatomical variation: opus I: muscular system: alphabetical listing of muscles: 1 . 2004:1-5.

14. Velasco MJR, Vasquez RJF, Velasco MJA, et al. Axillary arch: potential cause of neurovascular compression syndrome. Clin Anat 2003;16(6):514-9. 